\title{
Crise socioambiental e Teologia Pastoral: consolidação da mudança de paradigma à luz da Laudato Si'
}

\author{
Socio-environmental crisis and Pastoral Theology: \\ consolidation of the paradigm shift in the light of \\ Laudato $\mathrm{Si}^{\prime}$
}

Abimar Oliveira de Moraes

\section{Resumo}

A Teologia Pastoral, no curso dos poucos séculos de sua existência, passou por um intenso processo de desenvolvimento de sua concepção, de suas relações com os diversos modelos de igreja, de suas relações com a práxis eclesial e com os demais saberes científicos. De maneira especial, os pastoralistas começam a intuir e constatar que os fatores socializantes incidem profundamente sobre a existência humana e cristã. Por essa razão, a reflexão teológico-pastoral deve necessariamente levar em conta a estrutura coletiva de toda a realidade socioambiental. Assistimos, assim, a um importante movimento que leva a Teologia Pastoral a compreender que o autêntico "cuidado das almas" deve ser capaz de integrar-se num verdadeiro e autêntico cuidado com o ambiente. A pessoa humana - por sua própria natureza relacionada com os outros e com o seu "território" - recebe sustento, abertura, conteúdo vital e motivações para construir sua realização própria da "espacialidade" na qual o seu ser encontra-se, isto é, do seu contexto socioambiental. Objetivo desta pesquisa é refletir sobre como a atenção à crise socioambiental tal como descrita pela Laudato $\mathrm{Si}^{\prime}$, do papa Francisco, exige da Teologia Pastoral a consolidação de uma consciência ecológica integral, capaz de articular uma nova aliança entre pessoas humanas, sociedades e natureza, na direção da conservação do patrimônio 
terrestre, do bem comum sociocósmico e da manutenção das condições que consintam que o processo evolutivo do criado siga seu curso.

Palavras-chave: Teologia Pastoral. Ecologia integral. Laudato Si’.

\begin{abstract}
Pastoral Theology, in the course of the few centuries of its existence, went through an intense process of development of its conception, of its relations with the different models of the church, of its relations with ecclesial praxis and with other scientific knowledge. In a special way, pastoralists begin to intuit and see that socializing factors have a profound impact on human and Christian existence. For this reason, theologicalpastoral reflection must necessarily take into account the collective structure of the entire socio-environmental reality. We are witnessing, therefore, an important movement that leads Pastoral Theology to understand that the authentic "care of souls" must be able to be integrated in a true and authentic care for the environment. The human person - due to his own nature related to others and to his "territory" - receives sustainance, openness, vital content and motivations to build his own realization of the "spatiality" in which his being finds himself, that is, socio-environmental context. The objective of this research is to reflect on how the attention to the socio-environmental crisis as described by Pope Francis Laudato Si' demands from Pastoral Theology the consolidation of an integral ecological conscience, capable of articulating a new alliance between human beings, societies and nature in the direction of conservation of terrestrial heritage, the socio-economic common good and the maintenance of conditions that allow the evolutionary process of the creation to take its course.
\end{abstract}

Keywords: Pastoral Theology. Integral Ecology. Laudato Si'.

\title{
Introdução
}

Quem acompanha o debate acadêmico, pode perceber um importante movimento, instaurado na Área Ciências da Religião e Teologia, no Brasil, de investigação, de revisão e de consolidação de uma episteme nova para a 
Teologia,${ }^{1}$ sempre mais adequada aos desafios que - a nossa estreita cooperação com as Ciências da Religião, o reconhecimento da autonomia da Área (no ano de 2016) e o impacto que nossa produção de conhecimento precisa ter, nas mais diversificadas manifestações da assim chamada "esfera pública"2 - se nos impõe.

Nesse sentido, o que propomos neste artigo tem o escopo de contribuir para que não passemos à análise do diálogo da Teologia com outros saberes, ${ }^{3}$ sem também nos ocuparmos do diálogo interno à Teologia. Dentro da própria Teologia, é possível investigar como existem e como se dão as relações intra corpore. Tal investigação é de suma importância, pois enriquece e potencializa a Teologia, numa espécie de "passo para trás" que permite ao atleta realizar o mais perfeito "salto à frente".

Uma das disciplinas que mais evoluiu neste processo de diálogo interno foi a Teologia Pastoral. Na verdade, ao contrário de outras disciplinas

\footnotetext{
${ }^{1}$ Desde seu Primeiro Congresso, realizado em 2008, a Associação Nacional de Pósgraduação e Pesquisas em Teologia e Ciências da Religião (ANPTECRE), deu início a um importante movimento de debate acerca da epistemologia própria desses dois âmbitos do saber. Sobre os temas e os debates dos sete Congressos até então realizados visitar: https://www.anptecre.org.br/index.php?pagina=grupo_conteudo\&tela=31. Como fruto dos debates do primeiro e segundo Congresso da ANPTECRE, veio à luz a obra, organizada por Geraldo De Mori e Eduardo Cruz, "Teologia e Ciências da Religião": DE MORI, G., Introdução, p. 9-10. Do ponto de vista teológico, indicamos nesta obra os seguintes capítulos: GONÇALVES, P. S. L., O círculo hermenêutico na Teologia da Libertação, p. 175-197; SINNER, R. von., Hermenêutica em perspectiva teológica, p. 123-142; WALCHHOZ, W., Por uma Teologia como ciência e pela ecumene das ciências, p. 199-217. Outros estudos que podem contribuir para uma visão do debate acerca da episteme da Teologia no Brasil, especialmente a Teologia Prática: ADAM, J. C.; SCHMIEDT, V. S.; HERBES, N. E., Teologia Prática na Escola Superior de Teologia, p. 227-248; CARNEIRO DE ANDRADE, P. F., O reconhecimento da teologia como saber universitário, p. 21-36; HOSS, G. M.; PEREIRA, A. P., Teologia Pastoral na vida da Igreja Católica, p. 249-263; KUZMA, C., A teologia no universo científico e sua especificidade epistemológica, p. 231-247; MORAES, A., Entre mistério divino e humano, p. 149-179; OLIVEIRA, D. M.; CAMPOS, B., Teologia Prática Pentecostal, p. 264-275; SINNER, R. von, Teologia pública no Brasil, p. 264-276; VILLAS BOAS, A., Perspectiva interdisciplinar da Teologia no Brasil, p. 260-286.

${ }^{2}$ SINNER, R. von, Teologia pública no Brasil, p. 264-276.

${ }^{3}$ Não queremos negar que a reflexão teológica beneficamente passa por "um movimento de reconciliação com as realidades terrestres que busca compreender teologicamente as grandes questões teóricas e práticas elucidadas pela racionalidade moderna, tais como: a origem do ser humano (e as teorias científicas da evolução), o processo histórico (e as ciências históricas), as contradições sociais (e as ciências sociais), a diversidade cultural (e a antropologia), o comportamento humano (e a psicologia) e assim por diante" (PASSOS, J. D., Teologia e outros saberes, p. 125).
} 
teológicas, desde seu nascimento e primeiro desenvolvimento, o estatuto científico da Teologia Pastoral foi discutido e nesse processo de discussão sempre houve espaço para a reflexão de sua relação com outros setores que compõe a experiência de fé. ${ }^{4}$

Um dos objetivos deste artigo é dar continuidade ao mapeamento da evolução desta disciplina - chamada de Teologia Pastoral (para outros Teologia Prática $)^{5}$ - no quadro maior do sistema de produção de saber denominado Teologia. Consideramos esta tarefa importante para o debate em nossa Área, pois a dimensão pastoral ou prática da Teologia está presente na caracterização que a Capes apresenta para a Teologia em seu Documento de Área. ${ }^{6}$

Observemos, contudo, que a palavra "pastoral" é uma das mais usadas na linguagem teológica atual. Isto faz sim, com que corramos o risco de um uso tão amplo que acaba por não deixar claro ao que estamos fazendo menção. Não nos resta dúvida, portanto, que precisamos esclarecer o que entendemos por Teologia Pastoral, no cenário acadêmico brasileiro, para conseguirmos produzir pesquisas capazes de responder à natureza e à especificidade desta disciplina dentro do sistema teológico.

Ao falar da especificidade desta disciplina, Ramos Guerreira afirma:

A teologia pastoral tem: um âmbito: os estudos teológicos; uma referência próxima: a concepção eclesiológica; uma referência última: a fé da Igreja;

\footnotetext{
${ }^{4}$ Para um rápido balanço desse processo de discussão do estatuto científico da Teologia Pastoral até o final do século passado, ver: SZENTMÁRTONI, M., Introduzione alla Teologia Pastorale, p. 9-17.

${ }^{5}$ No Documento de Área de Ciências da Religião e Teologia da CAPES, a designação utilizada é Teologia Prática, com os seguintes temas correlatos: Psicologia pastoral, teologia e saúde, ecoteologia, fé e política, homilética, relação entre teologia/culto/práxis, missão e inculturação, inclusão e direitos humanos, teologia e sociedade, ação, experiência e conhecimento prático, educação na respectiva tradição, ver: CAPES, Documento de Área (2019), p. 4. No presente artigo, não distinguiremos os dois conceitos, tomando como base a argumentação acerca da configuração atual de Mario Midali (MIDALI, M., Teologia Pastorale o Pratica, p. 557-615).

${ }^{6}$ Assim se expressa o Documento: “o perfil do egresso de cursos de pós-graduação em Teologia deve considerar a formação de habilidades para que o concluinte seja capaz de: a) contribuir para o aprofundamento e expansão da reflexão teológica em geral, bem como para a interpretação de textos e linguagens da experiência religiosa de uma tradição; b) desenvolver cientificamente uma investigação sobre a experiência de fé de um determinado grupo; c) assessorar e formar especialistas e não especialistas de uma dada tradição espiritual; d) contribuir para a tradução dos conteúdos teológicos, culturais, morais e religiosos dessa tradição para sua cultura, seu tempo e o espaço público; e) desenvolver uma teologia da práxis" (CAPES, Documento de Área (2019), p. 5).
} 
um objeto: a ação da Igreja; dois campos: a ação considerada em si mesma ou em suas realizações históricas concretas; um método: a avaliação da situação concreta eclesial para, a partir da projeção de uma situação nova, traçar os imperativos básicos da ação; uma ajuda: as ciências auxiliares que, com caráter interdisciplinar, ajudam no conhecimento da realidade; uma finalidade próxima: iluminar a prática eclesial concreta e oferecer-lhe pautas para sua identificação; uma finalidade última: servir à missão eclesial. $^{7}$

Nesta sua definição, a primeira coisa que salta aos olhos é a afirmação de que a Teologia Pastoral é fundamentalmente Teologia, isto é, uma reflexão a partir da fé que toma em consideração as indicações da própria tradição religiosa, na tentativa de entrar em diálogo com as situações históricas do mundo. A ela compete o indagar, o tirar consequências práticas, o marcar caminhos e pautas de comportamento. Tudo isto, porém, sem perder de vista seu diálogo com a tradição e o magistério eclesial aos quais está vinculada, uma vez que a prática concreta é obra de todos os membros de uma determinada comunidade eclesial. A Teologia Pastoral, nesse sentido, se apresenta como um processo de estruturação, a partir de critérios científicos, de maneira crítica e sistemática, do vasto campo da práxis de uma determinada tradição religiosa. É dentro dessa perspectiva, que, para nós católicos, as indicações do magistério do papa Francisco na Laudato Si'apresentam-se como norteadoras do saber teológico pastoral que devemos produzir, estruturar e propor.

Porque distintos e complementares, ${ }^{8}$ Teologia Pastoral e magistério dialogam, a fim de que a Teologia Pastoral possa exercer uma função crítica no interior da vida da comunidade de fé católica, fazendo com que a mesma busque linhas fundamentais para a sua autorrealização ou autoedificação. ${ }^{9}$ Por isso, para Prat i Pons:

A Teologia Pastoral tem uma dimensão crítica uma vez que exerce uma tarefa de delimitação de objetivos, tarefas, atitudes, prioridades e sistemas organizativos eclesiais. Por sua natureza não é uma crítica subjetiva e idealista mas uma crítica que reconstrói a imagem eclesial autêntica; isto é, busca o marco teológico a partir do qual discernir o que fazemos, e fala

\footnotetext{
${ }^{7}$ RAMOS GUERREIRA, J. A., Teología pastoral, p. 14-15.

${ }^{8}$ ANTÓN, A., Magisterio y Teología, p. 351-382; LATOURELLE, R., Teologia scienza della salvezza, p. 63-64.

${ }^{9}$ Nesse artigo, não queremos nos deter nos influxos da Teologia Pastoral junto ao magistério.
} 
das condições da ação da Igreja e de sua imagem real, visando contribuir para a elaboração de seu desenvolvimento. ${ }^{10}$

O que queremos observar no presente artigo é, em que medida, a Laudato Si' é "ponto de chegada" de um percurso teológico-pastoral desenvolvido na América Latina e, principalmente, como ela - como texto magisterial vinculante para a comunidade eclesial católica - consolida um novo paradigma teológico-pastoral que aqui chamaremos de biocêntrico. Iniciaremos por apresentar um breve panorama do caminho percorrido pela disciplina. Em seguida, tentaremos observar algumas implicações pastorais presentes na encíclica. Por fim, proporemos a construção de uma consciência ecológica integral, nos termos da Laudato Si', como a tarefa central dos estudos teológico pastorais hodiernos.

\section{Breve panorama da Teologia Pastoral}

Enquanto disciplina teológica, a Pastoral tem uma história acadêmica reduzida. Seu nascimento e desenvolvimento estão unidos à moderna concepção eclesiológica e, como tal, têm um pouco mais de dois séculos de existência. Vale destacar que a Teologia Pastoral não possui uma história uniforme. Sua existência não abrange toda a história da experiência de fé cristã. Fundamentalmente, ela foi uma disciplina teológica que se desenvolveu nos países de língua germânica, especialmente na época do seu nascimento e de seu primeiro desenvolvimento. Sua chegada a outros países, inclusive no Brasil, foi posterior.

Ela nasce em 1774, no contexto da reforma universitária empreendida por Maria Teresa da Áustria. Três são os fatores históricos que configuram fortemente a sua orientação: a) a unilateralidade visível e hierárquica da teologia pós-tridentina em sua concepção eclesiológica que, em polêmica anti-protestante, se concentrou somente em alguns aspectos parciais da doutrina tradicional; b) o josefinismo do império austríaco que, em sua concepção absolutista, queria colocar a igreja a serviço de seu poder e como meio para mantê-lo; c) a decadência das ciências teológicas que, em virtude das polêmicas dos anos anteriores, giraram, com pouca vitalidade, em torno dos temas jurídicos e canônicos com fins claramente apologéticos.

Tudo isto faz com que ela nasça marcada por elementos que se repetiriam nos anos posteriores. Um deles diz respeito à exclusividade da pessoa do

${ }^{10}$ PRAT I PONS, R., Tratado de Teología Pastoral, p. 48. 
pastor, entendido como o ministro ordenado católico romano. Inicialmente a formação de tal ministro é o único objeto de estudo. Nele se concentra toda a atividade da igreja e a nova reforma universitária quer fazer dele um pastor bonus preparando-o à atividade pastoral. Os seus deveres estão agrupados em torno das tarefas (ou múnus) de ensinar (profeta), de santificar (sacerdote) e de governar (rei). O método de estudo é rigorosamente dedutivo.

Assim, esta nova disciplina teológica surge mais como uma arte e técnica do que como verdadeira ciência. Seu conteúdo é, sobretudo, um compêndio de normas paras as situações que o pastor pode encontrar no exercício de seu ministério. Sua razão de ser é, antes de tudo, pragmática e esta característica será passada adiante. Isto, porém, de maneira positiva, colocou em conexão a teologia cristã com a sociedade. Na base desta nova disciplina, a teologia cristã deixa de ser entendida como um saber científico à margem da vida, passando a ter uma função de iluminar a realidade. Além disso, tal realidade constituise como fundamento da ação pastoral, originando um processo, inclusive de revisão da imagem da igreja.

Assim, a Teologia Pastoral, no curso dos poucos séculos de sua existência, passou por um intenso processo de desenvolvimento de sua concepção, de suas relações com os diversos modelos de igreja, de suas relações com a práxis eclesial e com os demais saberes científicos. Em breves termos, é possível identificar quatro grandes perspectivas que gradualmente foram ampliando a compreensão do fazer teológico-pastoral cristão: 1) a perspectiva clerocêntrica; 2) a perspectiva eclesiocêntrica; 3) a perspectiva antropocêntrica; ${ }^{11}$ e 4 ) a perspectiva biocêntrica, mais recentemente.

\footnotetext{
${ }^{11}$ Quando do seu surgimento, a disciplina Teologia Pastoral tem como objetivo formar os seminaristas que, após quatro anos de estudos de teologia dogmática, deviam aprender, num quinto ano de estudo, a aplicar na prática pastoral paroquial os conteúdos oriundos desses primeiros estudos. Ela está centrada exclusivamente na figura do futuro candidato ao ministério ordenado. Mais tarde, com o avanço da Eclesiologia, tanto em campo católico, como protestante, a disciplina amplia seu horizonte e passa a ocupar-se com a ação da comunidade eclesial. Enquanto a Eclesiologia cuida da igreja em sua dimensão ad intra, isto é, em sua essência; cabe à Teologia Pastoral a função de estudar a mesma igreja em sua dimensão ad extra, isto é, em sua existência concreta. Mais tarde, com o avanço da dimensão ecumênica e inter-religiosa, e, principalmente, num cenário de primeira atenção à emergência do sujeito humano, a Teologia Pastoral, sem deixar de integrar as duas primeiras perspectivas, passa a considerar que o raio de ação pastoral de uma comunidade de cristã, vai para além da preparação de seus ministros e da própria comunidade. É preciso assumir a sociedade, num todo, como espaço de atuação pastoral. Para aprofundamento destas três primeiras perspectivas, ver: MIDALI, M., Teologia Pastorale o Pratica, p. 17-153. A quarta será objeto deste artigo.
} 
É necessário que surjam reflexões que se esforcem em situar a Teologia Pastoral nesta quarta perspectiva que está ainda em fase de elaboração/consolidação. Tal perspectiva responde aos problemas pastorais emergentes da atual crise socioambiental, elaborando um saber teológico que resulta necessariamente multidisciplinar e oferecendo um saber científico teológico de caráter prático (pastoral). É possível fazer tudo isto, sem perder de nosso horizonte a identidade e a qualificação teológica da disciplina. Em diálogo, ela se aperfeiçoa como saber teológico ortopráxico, superando a configuração que a estabelece como corolário ou em função "ancilar" em relação à Teologia bíblica e/ou sistemática e estabelecendo (principalmente) com às Humanidades uma colaboração e um diálogo interdisciplinar fecundo.

Em outras palavras, é necessário desenvolver pesquisas atentas ao fato de que os fatores sociais incidem profundamente sobre a existência humana e cristã. Por essa razão, a reflexão teológico-pastoral deve necessariamente levar em conta a estrutura coletiva de toda a realidade, aqui, incluída a realidade socioambiental e a atenção que a mesma demanda.

A construção de um saber teológico-pastoral exige diálogo interdisciplinar para conhecer o que está se passando e atuar adequadamente. Em nossos dias, no Brasil (e não só), já não domina o positivismo de corte fundamentalista ou radical que negava a cientificidade à Teologia. ${ }^{12}$ Há uma "porta aberta" ao diálogo interdisciplinar que permite que a investigação sobre a vida humana e

12 "Ao mesmo tempo que se originava e se consolidava o Departamento de Teologia da PUC-Rio, a academia brasileira viu surgir e passou a familiarizar-se com um novo conceito de ciência que pode ser caracterizado por três pontos de vistas: antropológico, teórico e sociocultural. Do ponto de vista antropológico, dentre outros aspectos, esse novo conceito de ciência exige, como padrão demonstrativo de cientificidade, que o pesquisador(a) demonstre neutralidade, abertura para eventuais críticas e intersubjetividade. Do ponto de vista teórico, passa a ser tido como científico no Brasil, tudo o que se apresente como um sistema dedutivo e condicional de afirmações hipotéticas, estruturado segundo as regras das deduções lógicas, baseado, porém, em experiências que possam ser verificadas por outras pessoas. O saber científico passa a estar fundado não somente sobre a verificação empírica, mas também, sobre a justificação lógica, fazendo com que a validade desse saber possa também ser de natureza hipotética. Do ponto de vista sociocultural, a ciência passa a ser entendida como um âmbito cultural autônomo e fortemente diversificado, como expressão de tantas pesquisas que são conduzidas simultaneamente, em solo nacional, como interação com outras importantes instituições sociais brasileiras (indústria, comércio, defesa, mobilidade, saúde, turismo, dentre outras), como totalidade de tantas áreas e possibilidades de investigação que originam gradualmente diversas disciplinas autônomas, mas coligadas entre si que têm em comum uma estrutura formal, mas não um princípio material" (MORAES, A., Entre mistério divino e humano, p. 160). 
sobre a sua relação com os demais seres se nutra de uma pluralidade harmônica de itinerários e de estilos que se cruzam entre si na unicidade da pessoa.

A este respeito assim se expressa João Paulo II:

Com o crescimento do diálogo e pesquisa comum, dar-se-á um progresso verso a mútua compreensão e uma gradual descoberta de interesses comuns que fornecerão as bases para ulteriores pesquisas e discussões. Pertence ao futuro estabelecer de que modo isto acontecerá. O que é importante [...] é que o diálogo deve continuar e progredir em profundidade e em amplitude. Neste processo devemos superar qualquer tipo de tendência regressiva que conduza na direção de formas de reducionismo unilateral, de medo e de auto-isolamento. Aquilo que é absolutamente importante é que cada uma das disciplinas continue enriquecendo-se, nutrindo-se e provocando a outra a ser sempre mais aquela que ela deve ser e a contribuir para a nossa visão do que somos e para onde caminhamos. ${ }^{13}$

De fato, o grande problema socioambiental pode ser abordado por disciplinas isoladas, mas, é necessário que encontremos pontes entre os saberes e um horizonte sapiencial em que:

Aos resultados científicos e tecnológicos se unem os valores filosóficos e éticos, que são manifestação característica e imprescindível da pessoa humana. O cientista está bem cônscio de que a busca da verdade, mesmo quando se refere a uma realidade limitada do mundo ou do homem, jamais termina; remete sempre para alguma coisa que está acima do objeto imediato dos estudos, para os interrogativos que abrem o acesso ao Mistério. ${ }^{14}$

A Teologia Pastoral é convidada, ainda mais, pela encíclica Laudato Si, do papa Francisco, a este diálogo interdisciplinar sustentado pela investigação. Os estudos teológicos pastorais, para além de sua necessária especialização, devem comprometer-se com a sociedade, com a vida humana e com o ambiente.

O que encontramos, na Laudato Si', é um interessante exercício de "teologia pública" ou, com uma fórmula mais abrangente, um exercício público de teologia que tem três aspectos que dialogam entre si: a) a disposição

\footnotetext{
${ }^{13}$ JOÃO PAULO II, PP., Lettera a Padre George V. Coyne. A tradução é nossa.
}

${ }^{14}$ FR 106. 
e habilidade de fazer-se inteligível, em público, elaborando uma posição que é compreensível para todos, mesmo os que possuem uma linguagem religiosa ou científica distinta; b) a acessibilidade pública que consiste na prática habitual de defender os diversos pontos de vista de um modo não sectário e não autoritário, criando um debate plural e fecundo; e c) o não perder a identidade teológica e católica ao fazer-se inteligível e acessível.

Inteligibilidade e acessibilidade, sem perda de identidade, exigem atenção ante três condições que podem impedir o debate público: a) a abstração, que perde o contexto do qual participa; b) o isolamento próprio de todo sectarismo; e c) a imposição que implica a colonização de quem se crer possuidor de toda a "verdade". ${ }^{15}$ A "terapia" para estas condições (tão presentes em discursos e práticas pastorais atuais) é o diálogo plural, aberto, honesto e sincero que a Laudato Si'pede à Teologia Pastoral.

Assistimos, assim, a um importante movimento que tem levado a Teologia Pastoral a compreender que o autêntico "cuidado das almas" deve ser capaz de integrar-se num verdadeiro e autêntico cuidado com o ambiente. A pessoa humana - por sua própria natureza relacionada com os outros e com o seu "território" - recebe sustento, abertura, conteúdo vital e motivações para construir sua realização própria da "espacialidade" na qual o seu ser encontrase, isto é, do seu contexto socioambiental.

\section{Algumas implicações pastorais da crise socioambiental à luz da Laudato Si'}

Temos aprendido, com Hans Jonas, que, até pouco tempo atrás, todas as éticas tinham como pressuposto que "o que tinha relevância ética era a relação direta do homem com o homem, incluindo a relação consigo mesmo". ${ }^{16} \mathrm{~A}$ relação com o mundo externo, entendida como dominação, no sentido de técnica, isto é, de capacidade produtiva, não fazia, até bem pouco tempo, parte da pauta ética.

Para a Laudato $S i$,' a tecnologia não é neutra, pois não podemos

\footnotetext{
${ }^{15}$ Para uma breve visão sobre a colonialidade do poder, do saber e do ser, ver: CUNHA, C. A. M., Teologia decolonial e epistemologias do Sul, p. 310-312. Cresce no cenário nacional o interesse pelo tema da Teologia decolonial, por essa razão, em 2019, a Sociedade de Teologia e Ciências da Religião (SOTER) realizou seu $32^{\circ}$ Congresso com o tema: Decolonialidade e práticas emancipatórias: novas perspectivas para a Área Ciências da Religião e Teologia. Os anais do Congresso podem ser encontrados em: http://www.soter.org.br/anais/32.pdf.

${ }^{16}$ JONAS, H., El principio de responsabilidad, p. 29.
} 
"considerar a natureza como algo separado de nós ou como uma mera moldura da nossa vida". ${ }^{17}$ Para o pontífice:

É preciso reconhecer que os produtos da técnica não são neutros, porque criam uma trama que acaba por condicionar os estilos de vida e orientam as possibilidades sociais na linha dos interesses de determinados grupos de poder. Certas opções, que parecem puramente instrumentais, na realidade são opções sobre o tipo de vida social que se pretende desenvolver. ${ }^{18}$

Se a função da ética é proteger as vulnerabilidades, hoje, é de necessária importância reconhecer que também a natureza é vulnerável (não só a pessoa humana). Poderíamos dizer mais. No atual contexto, a natureza apresenta-se extremamente vulnerável, é uma vítima da inclemência das ações humanas. Tal vulnerabilidade está registrada nos danos irreparáveis - ou reparáveis somente a longo prazo - que produzimos na biosfera. Dramaticamente vamos compreendendo que a ação humana comporta uma responsabilidade que se estende no tempo e no espaço e que nos remete, também, a esfera do que ultrapassa o humano.

O interesse pela construção da justiça social (tema tão caro à Teologia Pastoral latino-americana), por esta razão, está intimamente unido à questão ecológica, fazendo com que não seja possível pensar a "questão social" fora da questão socioambiental. ${ }^{19}$ Assim, o novo campo da ética leva ao princípio da justiça e solidariedade entre as gerações como chave hermenêutica da compreensão atual da justiça social e da solidariedade. ${ }^{20}$

\footnotetext{
${ }^{17}$ LS 139.

${ }^{18}$ LS 107.

${ }^{19}$ De fato, ao longo de sua trajetória histórica, a Doutrina Social da Igreja católica romana foi respondendo às diversas questões sociais epocais, como, por exemplo, a questão operária, cerne da Rerum novarum de Leão XIII, a construção de uma nova ordem mundial, com Pio XI, a questão antropológica com Paulo VI, João Paulo II e Bento XVI, até chegar ao problema da ecologia humana, cerne da Laudato Si'do papa Francisco.

${ }^{20}$ LS 160: "que tipo de mundo queremos deixar a quem vai suceder-nos, às crianças que estão a crescer? Esta pergunta não toca apenas o meio ambiente de maneira isolada, porque não se pode pôr a questão de forma fragmentária. Quando nos interrogamos acerca do mundo que queremos deixar, referimo-nos sobretudo à sua orientação geral, ao seu sentido, aos seus valores. [...] Com que finalidade passamos por este mundo? Para que viemos a esta vida? Para que trabalhamos e lutamos? Que necessidade tem de nós esta terra? Por isso, já não basta dizer que devemos preocupar-nos com as gerações futuras; exige-se ter consciência de que é a nossa própria dignidade que está em jogo. Somos nós os primeiros interessados em deixar um planeta habitável para a humanidade que nos vai suceder. Trata-se de um drama para nós mesmos, porque isto chama em causa o significado da nossa passagem por esta terra".
} 
Tal dimensão intergeracional põe em destaque que os problemas econômicos e sociais do presente não se podem realmente enfrentar sem garantir os fundamentos de vida para as gerações futuras. Não nos é suficiente mais um olhar intrageracional, mas é preciso pensar nas gerações futuras, sem esquecer dos pobres de hoje que não podem mais esperar. ${ }^{21}$

Dessa maneira, a Laudato Si' nos convida a uma compreensão do desenvolvimento sustentável atento às gerações futuras, mas que põe, porém, os empobrecidos do presente no centro. Deste modo, três aspectos necessitam ser integrados: a) um nível de bem estar (não somente econômico) crescente; b) que não esgote os recursos naturais; e c) que permita reparti-los de forma justa e solidária, tanto intra como intergeneracionalmente. Em outras palavras, é preciso completar o desenvolvimento sustentável com o desenvolvimento eco-solidário.

A solidariedade e a justiça tanto intra como intergeneracional exigem ser pensadas como justiça global, com instituições que atuem como sujeitos efetivos das demandas por equidade em nível global ou interdependente para favorecer e proteger os bens públicos ou comuns globais. São necessárias, assim, formas e instrumentos eficazes para uma governança global. ${ }^{22}$

Para o papa Francisco, não existem: "duas crises separadas: uma ambiental e outra social; mas uma única e complexa crise socioambiental. As diretrizes para a solução requerem uma abordagem integral para combater a pobreza, devolver a dignidade aos excluídos e, simultaneamente, cuidar da natureza". ${ }^{23}$ Tal abordagem é considerada uma (não única) "ecologia integral" que aglutina a ecologia ambiental, econômica e social, ${ }^{24}$ a cultural ${ }^{25} \mathrm{e}$ a da vida cotidiana. ${ }^{26}$

\section{Construir uma consciência ecológica integral: tarefa da Teologia Pastoral}

A comunidade cristã - como "corpo público" do Verbo feito carne e como "corpo responsável" por Sua sempre presença no mundo - tem a tarefa de desenvolver, cuidar e concretizar sua obra evangelizadora reconhecendo

\footnotetext{
${ }^{21}$ LS 159 .

${ }^{22}$ LS 174-175.

${ }^{23} \operatorname{LS} 139$.

${ }^{24}$ LS 138-142.

${ }^{25}$ LS 143-146.

${ }^{26}$ LS 147-155.
} 
as características do seu contexto socioambiental. Partindo, portanto, de uma inevitável e necessária interação entre pessoa e ambiente, o seu fazer pastoral é convidado a ser "cristianização do território" no qual a pessoa humana vive.

Somos desafiados a desenvolver uma reflexão teológico-prática sobre a dimensão planetária da vida cotidiana das pessoas concretas, amadurecendo, assim, a consciência sobre a presença desumanizadora de um pecado ecosocial que se agrava e atenta contra os fundamentos da Teologia Cristã. As comunidades cristãs (e não só) são chamadas a contribuir para a superação das contraposições do ser humano consigo mesmo, dos seres humanos entre si, do ser humano com os demais criados e, consequentemente, com a própria imagem do Deus Salvador/Criador de Jesus de Nazaré.

A atenção socioambiental permite à Teologia Pastoral, e à Teologia Cristã como um todo, colher o desafio prático da construção de uma consciência ecológica integral, capaz de articular uma nova aliança entre pessoas humanas, na direção da conservação do patrimônio terrestre, da tutela do bem comum sociocósmico e da manutenção das condições que consintam que o processo evolutivo do criado siga seu curso no respeito à dignidade de toda obra que sai das mãos de Deus e que não pode ser "dominada" pelo humano, em especial, o humano religioso.

Tal Ecologia Integral deve postular que as pessoas humanas, as sociedades e as culturas fazem parte de um "complexo ecológico", constituído pela relação que todos os seres viventes, naturais e culturais, estabelecem entre eles e com o contexto ambiental. Tal consciência ecológica integral abarca as questões econômicas, políticas, sociais, militares, educativas, urbanísticas, agrícolas, ideológicas, religiosas, dentre tantas outras, e pode encontrar na Laudato $S i$ ', do papa Francisco, uma importante referência, para ser pensada e construída, desde que não entendida como uma fonte teológica a ser acessada somente pelos teólogos católicos. ${ }^{27}$

A Teologia Pastoral pode contribuir para o desenvolvimento de ações pastorais pensadas não mais a partir de uma perspectiva clerocêntrica e/ ou eclesiocêntrica. Tampouco a partir de uma perspectiva antropocêntrica dominadora que violenta a natureza e a humanidade, especialmente, os mais pobres. Mas, sim, a Teologia Pastoral pode ajudar a comunidade cristã (e não só) a mover-se a partir de um novo paradigma cultural, ou seja, um novo modo de organizar todas as relações dos seres humanos entre si,

${ }^{27}$ LS 137-162. 
com os outros criados, tendo em conta as exigências da salvaguarda do criado, o bem comum socioambiental, numa perspectiva que chamamos de biocêntrica.

Um princípio básico de tal consciência ecológica integral pode ser a observação mais atenta da construção de relações baseadas na vegetabilia, isto é, no reino da natureza que agrupa as plantas. Tal observação poderia nos ajudar a repensar as lógicas da animalia, isto é, do reino biológico composto pelos animais e, em especial, redimensionando suas "práticas predatórias". Por esta razão, o papa Francisco considera que é preciso desencadear um processo de conversão ${ }^{28}$ que permita à pessoa humana reconhecer seu estado de criaturalidade juntamente com os demais seres vivos, reconhecendo, assim, "a figura de um Pai criador e único dono do mundo". ${ }^{29}$

Tarefa da Teologia Pastoral será contribuir para o surgimento de "um ser humano novo", ${ }^{30}$ que seja capaz de apreciar o valor das suas relações com todos os demais seres vivos. ${ }^{31}$ Baseado nesta verdade antropológicoteológica, o processo de construção de uma consciência ecológica integral passa pelo reconhecimento dos pecados contra os demais seres criados. Retomando a ideia do Patriarca Bartolomeu, o bispo de Roma assim se expressa:

\begin{abstract}
Quando os seres humanos destroem a biodiversidade na criação de Deus; quando os seres humanos comprometem a integridade da terra e contribuem para a mudança climática, desnudando a terra das suas florestas naturais ou destruindo as suas zonas húmidas; quando os seres humanos contaminam as águas, o solo, o ar... tudo isso é pecado. Porque um crime contra a natureza é um crime contra nós mesmos e um pecado contra Deus. ${ }^{32}$
\end{abstract}

Diante desta realidade, a Teologia Pastoral deve contribuir para que a comunidade crente passe por um processo de conversão humanitária, ${ }^{33}$ transformando mentalidades e comportamentos e construindo uma consciência ecológica integral que seja capaz de:

\footnotetext{
${ }^{28}$ LS 217.

${ }^{29} \operatorname{LS} 75$.

${ }^{30} \operatorname{LS} 118$.

${ }^{31}$ LS 119.

${ }^{32}$ LS 8.

${ }^{33}$ LS 202-219.
} 
passar do consumo ao sacrifício, da avidez à generosidade, do desperdício à capacidade de partilha, numa ascese que "significa aprender a dar, e não simplesmente renunciar. É um modo de amar, de passar pouco a pouco do que eu quero àquilo de que o mundo de Deus precisa. É libertação do medo, da avidez, da dependência". ${ }^{34}$

A Teologia Pastoral deve ajudar a comunidade de fé a refletir sobre como construir-se a si mesma a partir de um outro estilo de vida, não mais marcado pelo consumismo, pelo paradigma técnico-econômico, pela violência, pela destruição e pela injustiça. ${ }^{35}$

Tarefa da Teologia Pastoral será ajudar a comunidade cristã (e não só) a avançar na crescente consciência de que todos os seres criados formam uma só família. ${ }^{36}$ Superando, assim, as estruturas de pecado no qual indivíduos e comunidades se encontram sem sequer darem-se conta.

A "conscientização" 37 é um processo pastoral a ser perseguido pela reflexão teológica cristã, a fim de que a pessoa humana perceba suas relações estreitas com os demais, com os grupos humanos circunvizinhos, com a natureza-criada e com a história. É um processo de descoberta de sua capacidade de juízo crítico, ao qual a fé cristã pode apresentar uma contribuição inestimável. ${ }^{38}$

Tal consciência ecológica integral deve ser capaz de avaliar os condicionamentos sociais, ambientais e ideológicos para fazer com que a comunidade crente se reconheça "alienada" e se ponha em marcha de superação de tal situação alienante. A comunidade de fé se reconhece inserida numa "estrutura de pecado" que comporta a superação de uma consciência ideologicamente deformada sustentada por interesses econômicos e corporativos que justificam ideologicamente as práticas e os comportamentos que lesionam a vida em todas as suas mais diversas expressões, compreendida, é claro, a própria vida humana:

As atitudes que dificultam os caminhos de solução, mesmo entre os crentes, vão da negação do problema à indiferença, à resignação acomodada ou à confiança cega nas soluções técnicas. Precisamos de nova solidariedade

\footnotetext{
${ }^{34}$ LS 9.

${ }^{35}$ LS 203-204.

${ }^{36}$ LS 52.

${ }^{37}$ Usamos o termo "conscientização" tal como ele se encontra nas reflexões freirianas, isto é, como despertar da consciência social para a construção de um processo de transformação comunitária (FREIRE, P., Pedagogia do oprimido; FREIRE, P., Educação como prática da liberdade). ${ }^{38}$ LS 199.
} 
universal. Como disseram os bispos da África do Sul, "são necessários os talentos e o envolvimento de todos para reparar o dano causado pelos humanos sobre a criação de Deus". Todos podemos colaborar, como instrumentos de Deus, no cuidado da criação, cada um a partir da sua cultura, experiência, iniciativas e capacidades. ${ }^{39}$

Faz-se necessário que a reflexão teológico pastoral aponte "para outro estilo de vida", ${ }^{40}$ orientando corretamente o sentido de nossas vidas e de todo o criado, reconstruindo a aliança entre a humanidade e o ambiente, ${ }^{41}$ mediante um "pacto educativo" que saiba, mais do que inculcar "conhecimentos", criar hábitos a partir da crise socioambiental e de todas as suas problemáticas, que realmente modifiquem o ambiente.

Não nos é suficiente ter normas de caráter jurídico, se não existir um compromisso que se baseia nas "convicções e modos de sentir favoráveis ao cuidado do ambiente. É muito nobre assumir o dever de cuidar da criação com pequenas ações diárias, e é maravilhoso que a educação seja capaz de motivar para elas até dar forma a um estilo de vida". ${ }^{42}$ Tudo isto se expressa numa plêiade de gestos da vida cotidiana quais são:

Evitar o uso de plástico e papel, reduzir o consumo de água, diferenciar o lixo, cozinhar apenas aquilo que razoavelmente se poderá comer, tratar com desvelo os outros seres vivos, servir-se dos transportes públicos ou partilhar o mesmo veículo com várias pessoas, plantar árvores, apagar as luzes desnecessárias... Tudo isto faz parte duma criatividade generosa e dignificante, que põe a descoberto o melhor do ser humano. Voltar - com base em motivações profundas - a utilizar algo em vez de o desperdiçar rapidamente pode ser um ato de amor que exprime a nossa dignidade. ${ }^{43}$

Estas pequenas ações ecológicas, é óbvio que não irão mudar o mundo, porém, podem estimular-nos a crescer no cuidado do mundo e fazer surgir outras ações capazes de consolidar um novo paradigma acerca do ser humano, da vida, da sociedade e da relação com a natureza. ${ }^{44}$ Segundo a Laudato Si',

\footnotetext{
${ }^{39} \operatorname{LS} 14$.

${ }^{40}$ LS 203-208.

${ }^{41}$ LS 209-215.

${ }^{42}$ LS 211.

${ }^{43} \operatorname{LS} 211$.

${ }^{44}$ LS 215.
} 
tal conversão ecológica deve ser comunitária, fruto de uma pertença a igreja, comunidade redimida pelo Criador/Redentor de todas as coisas:

Cada criatura reflete algo de Deus e tem uma mensagem para nos transmitir, [...] Cristo assumiu em Si mesmo este mundo material e agora, ressuscitado, habita no íntimo de cada ser, envolvendo-o com o seu carinho e penetrando-o com a sua luz; [...] (n)o reconhecimento de que Deus criou o mundo, inscrevendo nele uma ordem e um dinamismo que o ser humano não tem o direito de ignorar. [...] Convido todos os cristãos a explicitar esta dimensão da sua conversão, permitindo que a força e a luz da graça recebida se estendam também à relação com as outras criaturas e com o mundo que os rodeia, e suscite aquela sublime fraternidade com a criação inteira que viveu, de maneira tão elucidativa, São Francisco de Assis. ${ }^{45}$

\section{Conclusão}

A crescente sensibilidade pela questão ecológica está ajudando à Teologia Pastoral, bem como o magistério católico romano, ${ }^{46}$ a tomar consciência das consequências práticas da relação (nesse caso má relação) da pessoa e da comunidade de fé com o seu habitat, favorecendo o aprofundamento da compreensão de que uma autêntica experiência de fé cristã resulta numa série de relacionamentos com outros seres criados que expressa-se em diversos níveis. Todos estes níveis estão intrinsicamente conexos.

A atenção a toda criação carece, ainda, de uma melhor realização por parte daqueles que vivenciam a fé cristã. Temos, também, a tarefa de desenvolver uma antropologia e, a partir dela, uma experiência pastoral, onde a pessoa humana seja capaz de se entender como um ser criado e chamado por Deus em Cristo.

Nesse cenário, a Teologia Pastoral pode, dentro do sistema teológico, evidenciar a estreita relação entre o cuidado com a casa comum, a dignidade universal da pessoa humana e a missão da comunidade de fé. De maneira especial, pode indicar como a opção preferencial pelos que sofrem (ecossistema incluído, porque um ser vivo) deve produzir um consciente processo de atenção e de cuidado não somente consigo, mas com a dramática situação da casa comum, em nossos dias.

\footnotetext{
${ }^{45} \operatorname{LS} 221$.

${ }^{46}$ O Magistério pela primeira vez se ocupou da questão ecológica no pontificado de Paulo VI, em 1971: OA 21.
} 
Em sua proposta, a Laudato $\mathrm{Si}^{\prime}$ - integrando e, até mesmo, superando diversas visões ecológicas (a da conservação das espécies em extinção; a da mera criação de reservas ecológicas; a de uma ecologia que se limita somente ao ambiente natural; dentre outras) - convida-nos à construção de uma ecologia integral, capaz de articular uma nova aliança entre as sociedades e a natureza e da qual emerja um processo de conservação do patrimônio terrestre, o bem comum sociocósmico e a manutenção das condições que permitam o processo evolutivo de seguir seu curso milenar.

A visão ecológico-integral da Laudato Si' entende que as sociedades e as culturas fazem parte do complexo ecológico. A ecologia integral é, portanto, entendida como a relação que os seres viventes, naturais e culturais, estabelecem entre eles e com o contexto ambiental. Nessa perspectiva holística, estão inseridas na reflexão ecológica as questões econômicas, políticas, sociais, militares, educativas, urbanísticas, agrícolas, ideológicas e, naturalmente, teológicas.

Trata-se, portanto, dentre outros aspectos, de uma visão ecológica pastoralpolítico-social, que põe em primeiro plano a pessoa humana, em interação com o ambiente natural e, em especial, às vítimas da agressão ecológica, isto é, os pobres da terra. Assumindo uma perspectiva biocêntrica, a Teologia Pastoral precisa ocupar-se com os problemas relativos à miséria social, aos cinturões de pobreza e miséria, à degradação do campo e do espaço urbano, às doenças, à falta de habitação e de educação, à concentração latifundiária, às técnicas agroindustriais, ao comércio internacional dos alimentos, à contaminação do ar e das águas, às ameaças à biodiversidade, dentre outras.

Diante de um cenário de dupla injustiça (social e ambiental), mas que, segundo a Laudato Si', são uma única e mesma injustiça - fruto da violência contra o ambiente -, a Teologia Pastoral precisa propor linhas de superação às várias formas de ameaça à vida que se apresentam à comunidade eclesial: biocídio (destruição da vida), ecocídio (destruição dos ecossistemas), genocídio (destruição da terra) etc. O enfrentamento e a superação de tais problemas apresentam-se como objetivo da Teologia Pastoral à luz da encíclica papal, na compreensão de que ambas as injustiças são correlatas e geradoras de tensões sociais, violências, doenças, desnutrição e morte.

Os estudos teológicos pastorais, assim, são convidados a confrontar-se e envolver-se com a crise, colocando-se ao lado dos pobres, que são as vítimas da injustiça socioambiental. Assim, como em outros momentos de seu fazer histórico, a Teologia Pastoral passaria a uma nova fase não mais marcada pela 
visão antropocêntrica - entendida como dominante e de violência contra a natureza e a humanidade. Trata-se, portanto, de dar vida a um novo paradigma de desenvolvimento teológico pastoral, ou seja, um novo modo de organizar todas as relações dos seres humanos entre si, com os outros seres criados e com Deus, tendo como ponto de referência as exigências da salvaguarda do criado. Uma visão capaz de articular a ideia do bem comum social com a do bem comum do ambiente, do ar, das águas, dos seres vivos etc.

Essa é uma fase ainda em elaboração e com propostas limitadas, uma vez que o desafio que se apresenta é enorme, enquanto envolve poderes que são maiores do que a comunidade eclesial. Poderes estes que são planetários, mas que precisam ser estimulados a compreender a importância de produzir um sistema socioeconômico internacional atento ao que seja suficiente e digno para todos.

Em âmbito teológico-pastoral ocorre: a) desenvolver uma reflexão acerca da dimensão planetária da vida cotidiana das pessoas concretas; b) amadurecer a consciência da presença desumanizante que é fruto de um pecado social, ecológico e ecosocial; c) pensar a evangelização em chave de salvação da vida, em suas mais variadas expressões; d) renovar a teologia da criação, fazendo com que ela seja capaz de ajudar na superação da contraposição entre seres humanos e mundo criado (uma vez que o ser humano é parte integrante do mundo); e) superar uma visão estática da natureza, uma vez que a mesma é um processo histórico fruto da intervenção humana, em positivo ou em negativo.

Nesse processo de elaboração desse novo tipo de saber, a Teologia Pastoral pode deixar-se inspirar pelas seguintes palavras do Papa Francisco que corroboram a preocupação do romano pontífice já expressa na Laudato Si':

A Amazónia é um todo plurinacional interligado, um grande bioma partilhado por nove países [...]. Todavia dirijo esta Exortação ao mundo inteiro. Faço-o, por um lado, para ajudar a despertar a estima e solicitude por esta terra, que também é "nossa", convidando-o a admirá-la e reconhecê-la como um mistério sagrado; e, por outro, porque a atenção da Igreja às problemáticas deste território obriga-nos a retomar brevemente algumas questões que não devemos esquecer e que podem servir de inspiração para outras regiões da terra enfrentarem os seus próprios desafios. Tudo o que a Igreja oferece deve encarnar-se de maneira original em cada lugar do mundo, para que a Esposa de Cristo adquira rostos multiformes que manifestem melhor a riqueza inesgotável da graça. Deve encarnar-se a pregação, deve encarnar-se a espiritualidade, devem encarnar-se as 
estruturas da Igreja. [...] Sonho com uma Amazónia que lute pelos direitos dos mais pobres, dos povos nativos, dos últimos, de modo que a sua voz seja ouvida e sua dignidade promovida. Sonho com uma Amazónia que preserve a riqueza cultural que a caracteriza e na qual brilha de maneira tão variada a beleza humana. Sonho com uma Amazónia que guarde zelosamente a sedutora beleza natural que a adorna, a vida transbordante que enche os seus rios e as suas florestas. Sonho com comunidades cristãs capazes de se devotar e encarnar de tal modo na Amazónia, que deem à Igreja rostos novos com traços amazónicos. ${ }^{47}$

É possível perceber, nas palavras de Francisco, como os fenômenos (os sonhos) sociais, culturais, ecológicos e eclesiais amazônicos, em maneira e modalidades diversificadas, atingem as "outras regiões da terra", levantando sérios interrogativos e constituindo-se como objeto de pesquisa teológicopastoral. Para Francisco, o olhar para a Amazônia, permite-nos enxergar o cenário no qual se coloca hoje o agir evangelizador da comunidade católica romana e onde é possível e necessário construir um projeto pastoral biocêntrico, ecológico integral.

\section{Referências bibliográficas}

ADAM, J. C.; SCHMIEDT, V. S.; HERBES, N. E. Teologia Prática na Escola Superior de Teologia: um legado a ser explorado. Estudos Teológicos, v.56, p. 227-248, jul./dez. 2016. Disponível em: <http://periodicos.est.edu.br/index. php/estudos_teologicos/article/view/2868/pdf > . Acesso em: 11 fev. 2020.

ANTÓN, A. Magisterio y Teología: dos funciones complementarias en la Iglesia. Seminarium, v.29, p. 351-382, jan./mar.1989.

CAPES. Documento de Área (2019). Área 44: Ciências da Religião e Teologia. Disponível em: <https://www.capes.gov.br/images/Documento_ de_\%C3\%A1rea_2019/ciencia_religiao_teologia.pdf $>$. Acesso em: 29 set. 2019. CARNEIRO DE ANDRADE, P. F. O reconhecimento da teologia como saber universitário: tensões e articulações entre as dimensões confessional e profissional. In: SOARES, A. M. L.; PASSOS, J. D. (Orgs.). Teologia Pública.

\footnotetext{
${ }^{47}$ Querida Amazônia, 5-7. Esclarecemos que, embora datada de 2 de fevereiro de 2020, a Exortação Pós-sinodal, só foi trazida a público no dia 12 do mesmo mês e ano. Para cumprir os prazos de submissão propostos pelo periódico, neste período, já levávamos a termo a reflexão presente neste artigo.
} 
Reflexões sobre uma área de conhecimento e sua cidadania acadêmica. São Paulo: Paulinas, 2011. p. 21-36.

CUNHA, C. A. M. Teologia decolonial e epistemologias do Sul. Interações, v.13, p. 306-333, ago./dez. 2018. Disponível em: <file://C:/Users/Teologis/ Downloads/18518-Texto\%20do\%20artigo-69073-1-10-20181231.pdf>. Acesso em: 14 fev. 2020.

DE MORI, G. Introdução. In: DE MORI, G.; CRUZ, E. (Orgs.). Teologia e Ciências da Religião. A caminho da maioridade acadêmica no Brasil. Belo Horizonte: PUC-Minas; São Paulo: Paulinas, 2011. p. 7-14.

FRANCISCO, PP. Carta Encíclica Laudato Si' sobre o cuidado da casa comum. Disponível em: <http://www.vatican.va/content/francesco/pt/ encyclicals/documents/papa-francesco_20150524_enciclica-laudato-si. html>. Acesso em: 29 set. 2019.

FRANCISCO, PP. Exortação Apostólica Pós-sinodal Querida Amazonia ao povo de Deus e a todas as pessoas de boa vontade. Disponível em: $<\mathrm{http}$ ://www.vatican.va/content/francesco/pt/apost_exhortations/documents/ papa-francesco_esortazione-ap_20200202_querida-amazonia.html\#A_ Amaz\%C3\%B3nia>. Acesso em: 27 fev. 2020.

FREIRE, P. Educação como prática da liberdade. Rio de Janeiro: Paz e Terra, 1967.

FREIRE, P. Pedagogia do oprimido. Rio de Janeiro: Paz e Terra, 1975.

GONÇALVES, P. S. L. O círculo hermenêutico na Teologia da Libertação. In: DE MORI, G.; CRUZ, E. (Orgs.). Teologia e Ciências da Religião. A caminho da maioridade acadêmica no Brasil. Belo Horizonte: PUC Minas; São Paulo: Paulinas, 2011. p. 175-197.

HOSS, G. M.; PEREIRA, A. P. Teologia Pastoral na vida da Igreja Católica. Estudos Teológicos, v.56, p. 249-263, jul/dez 2016. Disponível em: <http:// periodicos.est.edu.br/index.php/estudos_teologicos/article/view/2809/pdf > . Acesso em: 11 fev. 2020.

JOÃO PAULO II, PP. Carta Encíclia Fides et ratio. Disponível em: <http:// www.vatican.va/content/john-paul-ii/pt/encyclicals/documents/hf_jp-ii_ enc_14091998_fides-et-ratio.html\#-3N>. Acesso em: 10 fev. 2020.

JOÃO PAULO II, PP. Lettera a Padre George V. Coyne, Direttore della Specola Vaticana. Disponível em: $<$ http://www.vatican.va/content/john- 
paul-ii/it/letters/1988/documents/hf_jp-ii_let_19880601_padre-coyne.html>. Acesso em: 10 fev. 2020.

JONAS, H. EI principio de responsabilidad. Barcelona: Herder, 1995.

KUZMA, C., A teologia no universo científico e sua especificidade epistemológica. In: SOARES, A. M. L.; PASSOS, J. D. (Orgs.). Teologia Pública. Reflexões sobre uma área de conhecimento e sua cidadania acadêmica. São Paulo: Paulinas, 2011. p. 231-247.

LATOURELLE, R. Teologia scienza della salvezza. Assisi: Citadella, 2005.

MIDALI, M. Teologia Pastorale o Pratica. Cammino storico di una riflessione fondante e scientifica. Roma: LAS, 1991.

MORAES, A. Entre mistério divino e humano: cinquenta anos de pesquisa teológica na PUC-Rio. Atualidade Teológica, v.61, p. 149-179, jan./abr. 2019. Disponível em: <https://www.maxwell.vrac.puc-rio.br/37777/37777. PDFXXvmi=>. Acesso em: 30 set. 2019.

OLIVEIRA, D. M.; CAMPOS, B. Teologia Prática Pentecostal: particularidades, perfil e desafios no século XXI. Estudos Teológicos, v.56, p. 264-275, jul./dez. 2016. Disponível em: <http://periodicos.est.edu.br/index. php/estudos_teologicos/article/view/2833/pdf > . Acesso em: 11 fev. 2020.

PASSOS, J. D. Teologia e outros saberes. Uma introdução ao pensamento teológico. São Paulo: Paulinas, 2010.

PAULO VI, PP. Carta apostólica Octogesima adveniens ao senhor cardeal Maurício Roy, presidente do Conselho dos Leigos e da Pontifícia Comissão "Justiça e Paz" por ocasião do $\mathbf{8 0}^{\circ}$ aniversário da Encíclica Rerum Novarum. Disponível em: http://www.vatican.va/content/paul-vi/ pt/apost_letters/documents/hf_p-vi_apl_19710514_octogesima-adveniens. html>. Acesso em: 29 set. 2019.

PRAT I PONS, R. Tratado de Teología Pastoral. Compartir la alegría de la fe. Salamanca: Secretariado Trinitario, 1995.

RAMOS GUERREIRA, J. A. Teología pastoral. Madrid: BAC, 1995.

SINNER, R. von. Hermenêutica em perspectiva teológica. In: DE MORI, G.; CRUZ, E. (Orgs.). Teologia e Ciências da Religião. A caminho da maioridade acadêmica no Brasil. Belo Horizonte: PUC Minas; São Paulo: Paulinas, 2011. p. $123-142$. 
SINNER, R. von. Teologia pública no Brasil. In: SOARES, A. M. L.; PASSOS, J. D. (Orgs.). Teologia Pública. Reflexões sobre uma área de conhecimento e sua cidadania acadêmica. São Paulo: Paulinas, 2011. p. 264-276.

SZENTMÁRTONI, M. Introduzione alla Teologia Pastorale. Casale Monferrato (AL): Piemme, 1992.

VILLAS BOAS, A. Perspectiva interdisciplinar da Teologia no Brasil: O debate epistemológico da Área de Ciências da Religião e Teologia. Interações, v.13, p. 260-286, ago./dez. 2018. Disponível em: <file://C:/Users/Teologis/ Downloads/18656-Texto\%20do\%20artigo-69070-1-10-20181231.pdf>. Acesso em: 13 fev. 2020.

WALCHHOZ, W. Por uma Teologia como ciência e pela ecumene das ciências. In: DE MORI, G.; CRUZ, E. (Orgs.). Teologia e Ciências da Religião. A caminho da maioridade acadêmica no Brasil. Belo Horizonte: PUC Minas; São Paulo: Paulinas, 2011. p. 199-217.

\section{Abimar Oliveira de Moraes}

Doutor em Teologia pela Università Pontificia Salesiana de Roma Docente do Departamento de Teologia da Pontifícia Universidade

Católica do Rio de Janeiro Presidente do Conselho Diretor da Associação Nacional de Pós-graduação e Pesquisa em Teologia e Ciências da Religião Rio de Janeiro / RJ - Brasil E-mail: abimar@puc-rio.br

Recebido em: 04/03/2020

Aprovado em: 20/03/2020 